\title{
A high-resolution regional emission inventory of atmospheric mercury and its comparison with multi-scale inventories: a case study of Jiangsu, China
}

\author{
Hui Zhong ${ }^{1}$, Yu Zhao ${ }^{1,2}$, Marilena Muntean ${ }^{3}$, Lei Zhang ${ }^{4}$, and Jie Zhang ${ }^{2,5}$ \\ ${ }^{1}$ State Key Laboratory of Pollution Control \& Resource Reuse and School of the Environment, Nanjing University, \\ 163 Xianlin Ave., Nanjing, Jiangsu 210023, China \\ ${ }^{2}$ Jiangsu Collaborative Innovation Center of Atmospheric Environment and Equipment Technology (CICAEET), \\ Nanjing University of Information Science \& Technology, Jiangsu 210044, China \\ ${ }^{3}$ European Commission, Joint Research Centre, Institute for Environment and Sustainability, Air and Climate Unit, \\ Via E. Fermi, Ispra, Italy \\ ${ }^{4}$ University of Washington Bothell, 18115 Campus Way NE, Bothell, WA 98011, USA \\ ${ }^{5}$ Jiangsu Provincial Academy of Environmental Science, 176 North Jiangdong Rd., Nanjing, Jiangsu 210036, China
}

Correspondence to: Yu Zhao (yuzhao@nju.edu.cn)

Received: 20 June 2016 - Published in Atmos. Chem. Phys. Discuss.: 26 July 2016

Revised: 2 November 2016 - Accepted: 6 November 2016 - Published: 7 December 2016

\begin{abstract}
A better understanding of the discrepancies in multi-scale inventories could give an insight into their approaches and limitations as well as provide indications for further improvements; international, national, and plant-byplant data are primarily obtained to compile those inventories. In this study we develop a high-resolution inventory of $\mathrm{Hg}$ emissions at $0.05^{\circ} \times 0.05^{\circ}$ for Jiangsu, China, using a bottom-up approach and then compare the results with available global/national inventories. With detailed information on individual sources and the updated emission factors from field measurements applied, the annual $\mathrm{Hg}$ emissions of anthropogenic origin in Jiangsu in 2010 are estimated at $39105 \mathrm{~kg}$, of which 51,47 , and $2 \%$ were $\mathrm{Hg}^{0}, \mathrm{Hg}^{2+}$, and $\mathrm{Hg}^{\mathrm{p}}$, respectively. This provincial inventory is thoroughly compared to three downscaled national inventories (NJU, THU, and BNU) and two global ones (AMAP/UNEP and EDGARv4.tox2). Attributed to varied methods and data sources, clear information gaps exist in multi-scale inventories, leading to differences in the emission levels, speciation, and spatial distributions of atmospheric $\mathrm{Hg}$. The total emissions in the provincial inventory are 28, 7, 19, 22, and $70 \%$ larger than NJU, THU, BNU, AMAP/UNEP, and EDGARv4.tox2, respectively. For major sectors, including power generation, cement, iron and steel, and other coal com-
\end{abstract}

bustion, the $\mathrm{Hg}$ contents $(\mathrm{HgC})$ in coals/raw materials, abatement rates of air pollution control devices (APCDs) and activity levels are identified as the crucial parameters responsible for the differences in estimated emissions between inventories. Regarding speciated emissions, a larger fraction of $\mathrm{Hg}^{2+}$ is found in the provincial inventory than national and global inventories, resulting mainly from the results by the most recent domestic studies in which enhanced $\mathrm{Hg}^{2+}$ were measured for cement and iron and steel plants. Inconsistent information on large power and industrial plants is the main source of differences in spatial distribution of emissions between the provincial and other inventories, particularly in southern and northwestern Jiangsu, where intensive coal combustion and industry are located. Quantified with Monte Carlo simulation, uncertainties in the provincial inventory are smaller than those of the NJU national inventory, resulting mainly from the more accurate activity data of individual plants and the reduced uncertainties in $\mathrm{HgC}$ in coals/raw materials. 


\section{Introduction}

Mercury (Hg), known as a global pollutant, has received increasing attention for its toxicity and long-range transport. Identified as the most significant release into the environment (Pirrone and Mason, 2009; AMAP/UNEP, 2013), atmospheric $\mathrm{Hg}$ is analytically defined as gaseous elemental $\mathrm{Hg}\left(\mathrm{GEM}, \mathrm{Hg}^{0}\right)$, which has the longest lifetime and transport distance, and reactive gaseous mercury ( $\mathrm{RGM}, \mathrm{Hg}^{2+}$ ) and particle-bound mercury $\left(\mathrm{PBM}, \mathrm{Hg}^{\mathrm{p}}\right)$, which are more affected by local sources. Improved estimates in emissions of speciated atmospheric $\mathrm{Hg}$ are believed to be essential for better understanding the global transport, chemical behaviors, and mass balance of $\mathrm{Hg}$.

Due mainly to the fast growth in economy and intensive use of fossil fuels, China has been indicated as the highest ranking nation in anthropogenic $\mathrm{Hg}$ emissions (Fu et al., 2012; Pacyna et al., 2010; Pirrone et al., 2010). Emissions of speciated atmospheric $\mathrm{Hg}$ of anthropogenic origin in China have been estimated at both global and national scales. For example, AMAP/UNEP (2013) and Muntean et al. (2014) developed global Hg inventories which reported national emissions for China for 2010 and from 1970 to 2008, respectively. At the national scale, $\mathrm{Hg}$ emissions have been estimated based on more detailed provincial information on energy consumption and industrial production. Zhang et al. (2015), Zhao et al. (2015a), and Tian et al. (2015) evaluated the inter-annual trends in emissions for 2000-2010, 2005-2012, and 1949-2012, respectively, to explore the benefits of air pollution control polices, particularly for recent years.

There are considerable information gaps between inventories, attributed mainly to the data of different sources and levels of details. For coal-fired power plants (CPP), as an example, the global inventories by AMAP/UNEP (2013) and Muntean et al. (2014) obtained the national coal consumption from the International Energy Agency (IEA), and they acquired the information on control technologies from the "national comments" by selected experts and World Electric Power Plants (WEPP) database, respectively. In the national inventories by Zhang et al. (2015) and Tian et al. (2015), coal consumption of CPP by province was derived from official energy statistics, and the penetrations of flue gas desulfurization (FGD) systems were assumed at provincial level. Zhao et al. (2015a) further analyzed the activity data and emission control levels plant by plant using a "unit-based" database of power sector. Although data of varied sources and levels of details result in discrepancies between inventories, those discrepancies and the underlying reasons have not been thoroughly analyzed in previous studies, leading to large uncertainty in $\mathrm{Hg}$ emission estimation.

Existing global and national inventories could hardly provide satisfying estimates in speciated $\mathrm{Hg}$ emissions or well capture the spatial distribution of emissions at regional/local scales, attributed mainly to relatively weak investigation of individual sources. When they are used in a chemistry transport model (CTM), downscaled inventories at global/national scales would possibly bias the simulation at smaller scales. Improvement in emission estimation at local scale, particularly for the large point sources, is thus crucial for better understanding the atmospheric processes of $\mathrm{Hg}$ (Lin et al., 2010; Wang et al., 2014; Zhu et al., 2015). While local information based on sufficient surveys is proven to have advantages in improving the emission estimates for given pollutants like $\mathrm{NO}_{x}$ and $\mathrm{PM}_{10}$ (Zhao et al., 2015b; Timmermans et al., 2013), there are currently very few studies on $\mathrm{Hg}$ emissions at regional/local scales in China, and the differences of multi-scale inventories remain unclear.

In this work, therefore, we select Jiangsu, one of the most developed provinces with serious air pollution in China, as study area. Firstly, we develop a high-resolution Hg emission inventory of anthropogenic origin for 2010, based on a comprehensive review of field measurements and detailed information on emission sources. That provincial inventory is then compared to selected global and national inventories with a thorough analysis on data and methods. Discrepancies in emission levels, speciation, and spatial distributions are evaluated and the underlying sources of the discrepancies are figured out. Finally, the uncertainty in the provincial emission inventory is quantified and the key parameters contributing to the uncertainty are identified. The results provide an insight into the effects of varied approaches and data on development of the $\mathrm{Hg}$ emission inventory and indicate the limitations of current studies and the orientations for further improvement on emission estimation at regional/local scales.

\section{Data and methods}

\subsection{Data sources of multi-scale inventories}

As shown in Fig. S1 in the Supplement, Jiangsu province $\left(30^{\circ} 45^{\prime}-35^{\circ} 20^{\prime} \mathrm{N}, 116^{\circ} 18^{\prime}-121^{\circ} 57^{\prime} \mathrm{E}\right)$ is located in the Yangtze River Delta in eastern China and covers 13 cities. The Hg emissions of Jiangsu are obtained from two approaches: downscaled from global/national inventories and estimated using a bottom-up method with information on local sources incorporated.

In global/national inventories, $\mathrm{Hg}$ emissions were first calculated by sector based on activity data and emission factors that were obtained or assumed at global, national, or provincial level, and were then downscaled to regional domain with finer spatial resolution. Various methods and data were adopted in multi-scale inventories to estimate $\mathrm{Hg}$ emissions for different sectors, as summarized briefly in Table S1 in the Supplement. Three national inventories were developed by Nanjing University (NJU; Zhao et al., 2015a), Beijing Normal University (BNU; Tian et al., 2015), and Tsinghua University (THU; Zhang et al., 2015), with major activity data at provincial level obtained from Chinese na- 
tional official statistics. Compared to the NJU and BNU inventories, which applied deterministic parameters relevant to emission factors, THU developed a model with probabilistic technology-based emission factors to calculate the emissions. Based on international activity statistics at national level, two global inventories for 2010 were developed by the joint expert group of the Arctic Monitoring and Assessment Programme and United Nations Environment Programme (AMAP/UNEP, 2013) and the Emission Database for Global Atmospheric Research (EDGARv4.tox2, unpublished). The AMAP/UNEP inventory developed a new system for estimating emissions from main sectors based on a mass-balance approach with data on unabated emission factors and emission reduction technology employed in different countries. The EDGARv4.tox 2 inventory calculated the emissions for all the countries by primarily applying emission factors from EEA (2009) and USEPA (2012), combined with regional technology-specific information on emission abatement measures.

\subsection{Development of the provincial inventory}

In contrast to the downscaling approach, the emissions are calculated plant by plant based on information on individual sources and then aggregated to provincial level in a bottomup method. We refer to the inventory as the bottom-up or provincial inventory hereinafter. Information for individual emission sources are thoroughly obtained from the Pollution Source Census (PSC, internal data from the Environmental Protection Agency of Jiangsu Province). The PSC was conducted by local environmental protection agencies, in which the data for individual sources were collected and compiled through on-site investigation, including manufacturing technology, production level, energy consumption, fuel quality, and emission control devices. Differences in total energy consumption and industrial production levels exist between the PSC data and the energy/economic statistics. For example, the coal consumption by power plants in the PSC was $6 \%$ larger than the provincial statistics for Jiangsu in 2010. We believe that, compared to the energy and economic statistics that were commonly used in global/national inventories, the plant-by-plant PSC data could provide more detailed and accurate information on specific emitters, particularly for power and industrial plants.

According to the availability of data, anthropogenic sources are classified into three main categories. Category 1 includes coal-fired power plants (CPP), iron and steel plants (ISP), cement production (CEM), and other industrial coal combustion (OIB). Note that the emissions from coal combustion in cement production are not included in CEM but in OIB, following most other inventories included in this paper for easier comparison. The information on geographic location, activity levels (consumption of energy or raw materials), and penetration of air pollution control devices (APCDs) is compiled plant by plant from the PSC, with an exception that the technology employed in CEM is obtained from CCA (2011). Category 2 includes nonferrous metal smelting (NMS), aluminum production (AP), municipal solid waste incineration (MSWI), and intentional use sector (IUS: thermometer, fluorescent lamp, battery, and polyvinyl chloride polymer production). Geographic location information for those sources is obtained from the PSC, while other activity data come from official statistics at provincial level. Category 3 includes emission sources that are not contained in the PSC: residential and commercial coal combustion (RCC), oil and gas combustion $(\mathrm{O} \& \mathrm{G})$, biofuel use/biomass open burning (BIO), rural solid waste incineration (RSWI), and human cremation (HC). They are defined as area sources, and the data sources for them are discussed later in this section.

In general, annual emissions of total and speciated $\mathrm{Hg}$ are calculated using Eqs. (1) and (2), respectively:

$$
\begin{aligned}
& E=\sum_{n} \mathrm{AL}_{n} \times \mathrm{EF}_{n}, \\
& E_{s}=\sum_{n} \mathrm{AL}_{n} \times \mathrm{EF}_{n} \times F_{n, s},
\end{aligned}
$$

where $E$ is the $\mathrm{Hg}$ emission, $\mathrm{AL}$ is the activity levels (fuel consumption or industrial production), $\mathrm{EF}$ is the combined emission factor (emissions per unit of activity level), $F$ is the mass fraction of a given $\mathrm{Hg}$ speciation, and $n$ and $s$ represent emission source type and $\mathrm{Hg}$ speciation $\left(\mathrm{Hg}^{0}, \mathrm{Hg}^{2+}\right.$ or $\left.\mathrm{Hg}^{\mathrm{p}}\right)$.

For CPP/OIB and CEM, Eq. (1) can be revised to Eqs. (3) and (4), respectively, with detailed fuel and technology information on individual sources incorporated:

$$
\begin{aligned}
& E_{\mathrm{CPP} / \mathrm{OIB}}=\sum_{t} \sum_{i} \sum_{k} \mathrm{AL}_{i} \times \mathrm{HgC}_{k} \times \mathrm{RR}_{t} \times\left(1-\mathrm{RE}_{t}\right) \\
& E_{\mathrm{CEM}}=\sum_{t} \sum_{i}\left(\mathrm{AL}_{\text {Limestone }} \times \mathrm{HgC}_{\text {Limestone }}+\mathrm{AL}_{\text {Other }, i}\right. \\
& \left.\quad \times \mathrm{HgC}_{\text {Other }}\right) \times\left(1-\mathrm{RE}_{t}\right),
\end{aligned}
$$

where $\mathrm{HgC}$ is the $\mathrm{Hg}$ content of coal consumed in Jiangsu, calculated based on measured $\mathrm{Hg}$ contents of coal mines across the country and an inter-provincial flow model of coal transport (Zhang et al., 2015); $\mathrm{HgC}_{\text {Limestone }}$ and $\mathrm{HgC}_{\text {Other }}$ represent $\mathrm{Hg}$ contents of limestone and other raw materials (e.g., malmstone and iron powder) in cement production, respectively; RR is the $\mathrm{Hg}$ release ratios from combustors; $\mathrm{RE}$ is $\mathrm{Hg}$ removal efficiency of APCDs; $\mathrm{AL}_{\text {Limestone }}$ and $\mathrm{AL}$ Other represent the consumption of limestone and other raw materials in CEM, respectively; $i$ and $k$ represent individual point source and coal type, respectively; and $t$ represents APCD type, including wet scrubber (WET), cyclone (CYC), fabric filter (FF), electrostatic precipitator (ESP), FGD, and selective catalyst reduction (SCR) systems for CPP, as well as dry-process precalciner technology with dust recycling (DPT + DR), shaft kiln technology (SKT), and rotary kiln technology (RKT) with ESP or FF for CEM. Note that the $\mathrm{AL}$ for an individual CEM plant is calculated based on 
clinker and cement production when the information on limestone or other raw materials is missing in the PSC.

For ISP, Eq. (1) could be revised to Eq. (5):

$E_{\mathrm{ISP}}=\sum_{i}\left(\mathrm{AL}_{\text {steel }, i}+\mathrm{AL}_{\mathrm{iron}, i} \times R\right) \times \mathrm{EF}_{\text {steel }}$,

where $\mathrm{AL}_{\text {steel }}$ and $\mathrm{AL}_{\text {iron }}$ represent crude steel and pig iron production in ISP, respectively; $R$ is the liquid steel to hot metal ratio provided by Remus et al. (2012), converting the production of pig iron to crude steel equivalent; and $\mathrm{EF}_{\text {steel }}$ is the $\mathrm{Hg}$ emission factor applied to steel making, obtained from recent domestic tests by Wang et al. (2016).

Activity data for NMS, AP, MSWI, RCC, and O\&G are derived from national statistics (NMIA, 2011; NSB, 2011a, b), while $\mathrm{Hg}$ consumption in IUS is estimated based on the internal association commercial reports that provide national market and economy information collected at http: //www.askci.com/. Activity data for MSWI, RSWI, and BIO are taken following Zhao et al. (2015a). Other information, including control efficiencies of APCDs, speciation profiles, and emission factors inherited from previous studies, is summarized in Tables S2-S4 in the Supplement.

Regarding the spatial pattern of emissions, the study domain is divided into 4212 grid cells with a resolution at $0.05^{\circ} \times 0.05^{\circ}$. For categories 1 and 2 , emissions are directly allocated into corresponding grid cells according to the locations of individual sources. As considerable errors in plant locations were unexpectedly found in the PSC, the geographic locations for point sources with emissions more than $15 \mathrm{~kg}$ have been corrected by Google Maps. As a result, 900 plants in total are relocated, accounting for $14 \%$ of all the point sources. For Category 3, emissions are allocated according to the population density in urban areas (RCC) and that in rural areas (BIO and RSWI).

\subsection{Sensitivity and uncertainty analysis of emissions}

For better understanding the sources of discrepancies between inventories, a comprehensive sensitivity analysis is conducted to quantify the differences between selected parameters used in multi-scale inventories and the subsequent changes in emission estimation for Category 1 sources. The relative change $(\mathrm{RC})$ in a given parameter $(j)$ in global/national inventories compared to that in the provincial bottom-up inventory, as well as the changes in emissions for a selected source $(n)$ when the value of parameter $j$ in the bottom-up inventory is replaced by that in global/national inventories $\left(E_{\mathrm{diff}, n}\right)$, can be calculated using Eqs. (6) and (7), respectively:

$\mathrm{RC}_{j}=\frac{\mathrm{VO}_{j}-\mathrm{VB}_{j}}{\mathrm{VB}_{j}}$,
$E_{\text {diff }, n}=\mathrm{EO}_{n}-\mathrm{EB}_{n}$,

where $\mathrm{VB}$ is the value of parameters in the bottom-up inventory; VO is the value of parameters in other national/global inventories; $\mathrm{EB}$ is $\mathrm{Hg}$ emissions for a given sector in the bottom-up inventory; $\mathrm{EO}$ is $\mathrm{Hg}$ emissions for a given sector when the values of parameters in the bottom-up inventory are replaced by those in other global/national inventories; and $j$ and $n$ represent given parameter and source type, respectively.

In particular, a new parameter, total abatement rate (TA), is defined for the sensitivity analysis, combining the effect of the penetrations of APCDs and their removal efficiencies on emission abatement:

$\mathrm{TA}=\sum_{t} \mathrm{AR}_{t} \times \mathrm{RE}_{t}$

where $t$ represents APCD type and AR and RE are the application rate and $\mathrm{Hg}$ removal efficiency, with detailed information provided in Table S5 in the Supplement.

The uncertainties in speciated $\mathrm{Hg}$ emissions at provincial level are quantified using a Monte Carlo framework (Zhao et al., 2011). Given the relatively accurate data reported in the PSC, the probability distributions of activity levels for individual plants of CPP, OIB, ISP, and CEM are defined as normal distributions with the relative standard deviations set at 10, 20, 20, and $20 \%$ respectively. As summarized in Tables S6 and S7 in the Supplement, a database for Hg emission factors/related parameters by sector and speciation is established for China, with the uncertainties analyzed and indicated by probability distribution function (PDF). The PDFs of $\mathrm{Hg}$ contents in coal mines by province are obtained from Zhang et al. (2015). For Hg content in limestone ( $\left.\mathrm{HgC}_{\text {Limestone }}\right)$, a lognormal distribution is generated with bootstrap simulation based on 17 field tests by Yang (2014), as shown in Fig. S2 in the Supplement. For the rest of the parameters, a comprehensive analysis of uncertainties was conducted, incorporating the data from available field measurements as described in Zhao et al. (2015a). Ten thousand simulations are performed to estimate the uncertainties in emissions, and the parameters that are most significant in determination of the uncertainties are identified by source type according to the rank of their contributions to variance.

\section{Results and discussions}

\subsection{Emission estimation and comparison by sector}

\subsubsection{The total Hg emissions from multi-scale inventories}

Table 1 provides the $\mathrm{Hg}$ emissions by sector and species for Jiangsu in 2010 estimated from the bottom-up approach. The provincial total $\mathrm{Hg}$ emissions of anthropogenic origin are calculated to be $39105 \mathrm{~kg}$, of which $51 \%$ is released as $\mathrm{Hg}^{0}$, $47 \%$ as $\mathrm{Hg}^{2+}$, and $2 \%$ as $\mathrm{Hg}^{\mathrm{p}}$. In general, categories 1,2 , and 3 account for 90,4 , and $6 \%$ of the total emissions, respectively. CPP and CEM are the largest contributors to the 
total $\mathrm{Hg}\left(\mathrm{Hg}^{\mathrm{T}}\right)$ emissions. For $\mathrm{Hg}^{0}, \mathrm{Hg}^{2+}$, and $\mathrm{Hg}^{\mathrm{P}}$, the sectors with the largest emissions are CPP, CEM, and OIB respectively.

To better understand the discrepancies and their sources between various studies, the emissions from multi-scale inventories are summarized in Table 1 for comparison. Among all the inventories, the total emissions in the provincial inventory are the largest, i.e., $28,7,19,22$, and $70 \%$ higher than NJU, THU, BNU, AMAP/UNEP, and EDGARv4.tox2, respectively. The elevated $\mathrm{Hg}$ emissions compared to previous studies could be supported by modeling and observation work to some extent. Based on the chemistry transport modeling using GEOS-Chem (Wang et al., 2014), or correlation slopes with certain tracers $\left(\mathrm{CO}, \mathrm{CO}_{2}\right.$, and $\left.\mathrm{CH}_{4}\right)$ from ground observation (Fu et al., 2015), underestimation was suggested for the regional $\mathrm{Hg}$ emissions of anthropogenic origin in China.

Direct comparison between inventories is unavailable for every sector, as the definition of source categories is not fully consistent with each other. Therefore, necessary assumption and modification are made on source classification for global inventories. In Table 1, CPP, OIB, and RCC for EDGARv4.tox2 represent the emissions for all of the fossil fuel types, and they are 1316 and $5342 \mathrm{~kg}$ lower and $986 \mathrm{~kg}$ higher than our estimation from coal combustion, respectively. For AMAP/UNEP, the emissions from regrouped stationary combustion (industrial sources excluded), industry, and intentional use and product-waste-associated sources (see Table 1 for the detailed definition) are respectively 3382 and $2032 \mathrm{~kg}$ higher and $3118 \mathrm{~kg}$ lower than our estimation with the bottom-up method. Figure 1 shows the ratios of the estimated $\mathrm{Hg}$ emissions in national/global inventories to those in the provincial inventory by source. The CPP emissions are relatively close to each other, but larger differences exist in some other sources. The estimates for CEM and ISP in the provincial inventory are much higher than the NJU, BNU, and EDGARv4.tox2 inventories, while those for NMS are considerably smaller. The reasons for those differences are analyzed in detail in Sect. 3.1.2-3.1.4.

\subsubsection{Sensitivity analysis for power plants and industrial boilers}

Figure $2 \mathrm{a}$ and $\mathrm{b}$ represent the relative changes in given parameters between the provincial and other inventories, and the subsequent differences in $\mathrm{Hg}$ emissions for Category 1 sources, using Eqs. (6) and (7), respectively. For CPP, the differences between provincial and national/global inventories are mainly determined by $\mathrm{AL}, \mathrm{HgC}, \mathrm{TA}$, and IEF (integrated emission factors), as indicated by the calculation methods summarized in Table S1. (Instead of analyzing $\mathrm{HgC}$ and $\mathrm{RR}$ separately, integrated input emission factors were applied in AMAP/UNEP and EDGARv4.tox2.) For activity level (AL), the coal consumption data are collected and compiled plant by plant in the provincial inventory, while they were obtained

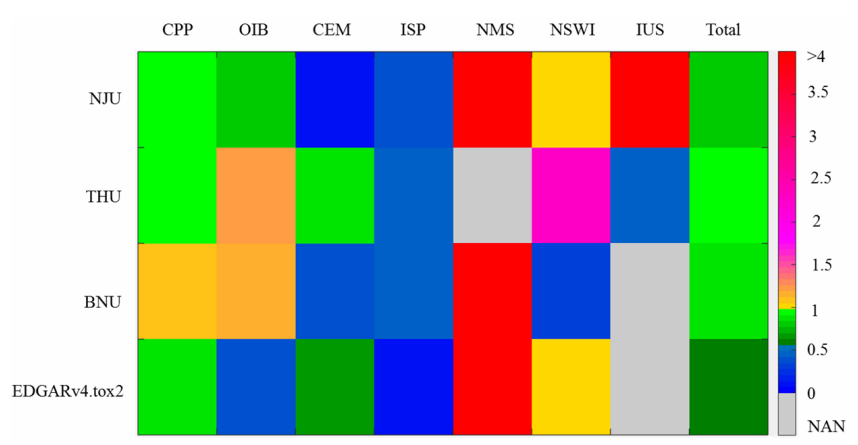

Figure 1. The ratios of estimated $\mathrm{Hg}$ emissions for Jiangsu and 2010 in global/national inventories to that in the provincial inventory for selected sources and anthropogenic total.
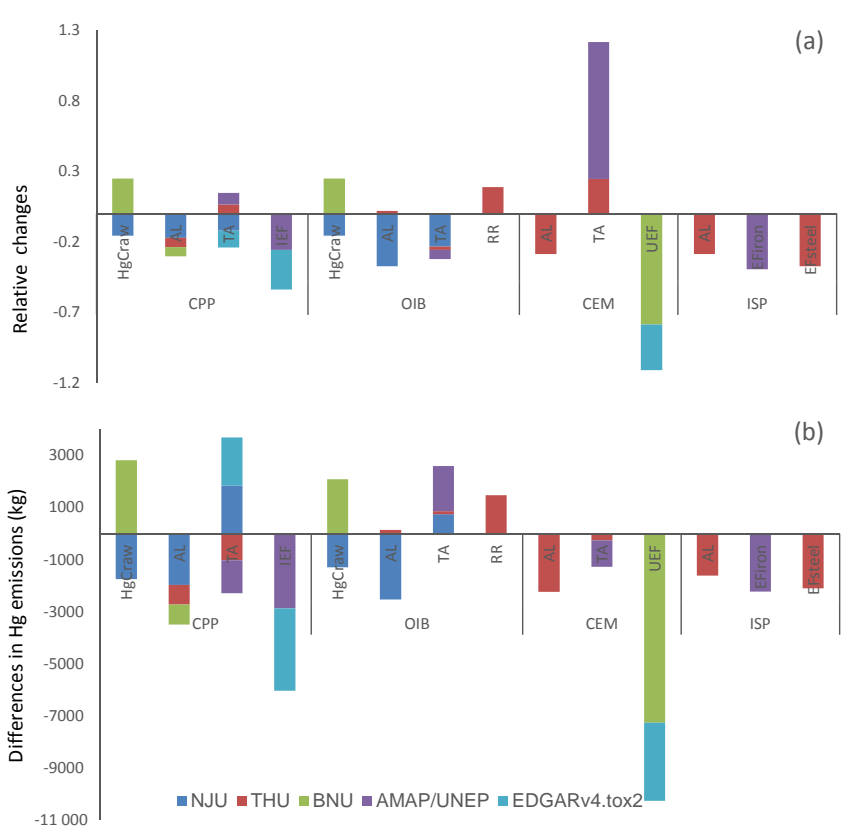

Figure 2. Sensitivity analysis of selected parameters in $\mathrm{Hg}$ emission estimation for Category 1 sources. (a) Relative changes in parameters, calculated using Eq. (6), and (b) changes in emissions when parameters in the provincial inventory were replaced with those in other inventories, calculated using Eq. (7). $\mathrm{HgC}_{\text {raw }}$ : $\mathrm{Hg}$ content in raw coal; AL: activity levels as raw coal consumption by CPP and OIB, limestone used by CEM, and crude steel produced in ISPs; TA: total abatement rate of APCDs; RR: Hg release rate for combustion; IEF: input emission factors (before control of APCDs); UEF: uniform emission factor (without consideration of different APCD types); $\mathrm{EF}_{\text {iron }}$ and $\mathrm{EF}_{\text {steel }}$ : emission factors of pig iron and steel production, respectively.

from Chinese official statistics (NSB, 2011b) in national inventories. As a result, the coal consumptions in the NJU and THU inventories are 17 and $6 \%$ smaller than our provincial inventory, resulting in 1968 and $760 \mathrm{~kg}$ reduction in $\mathrm{Hg}$ emission estimate, respectively. 


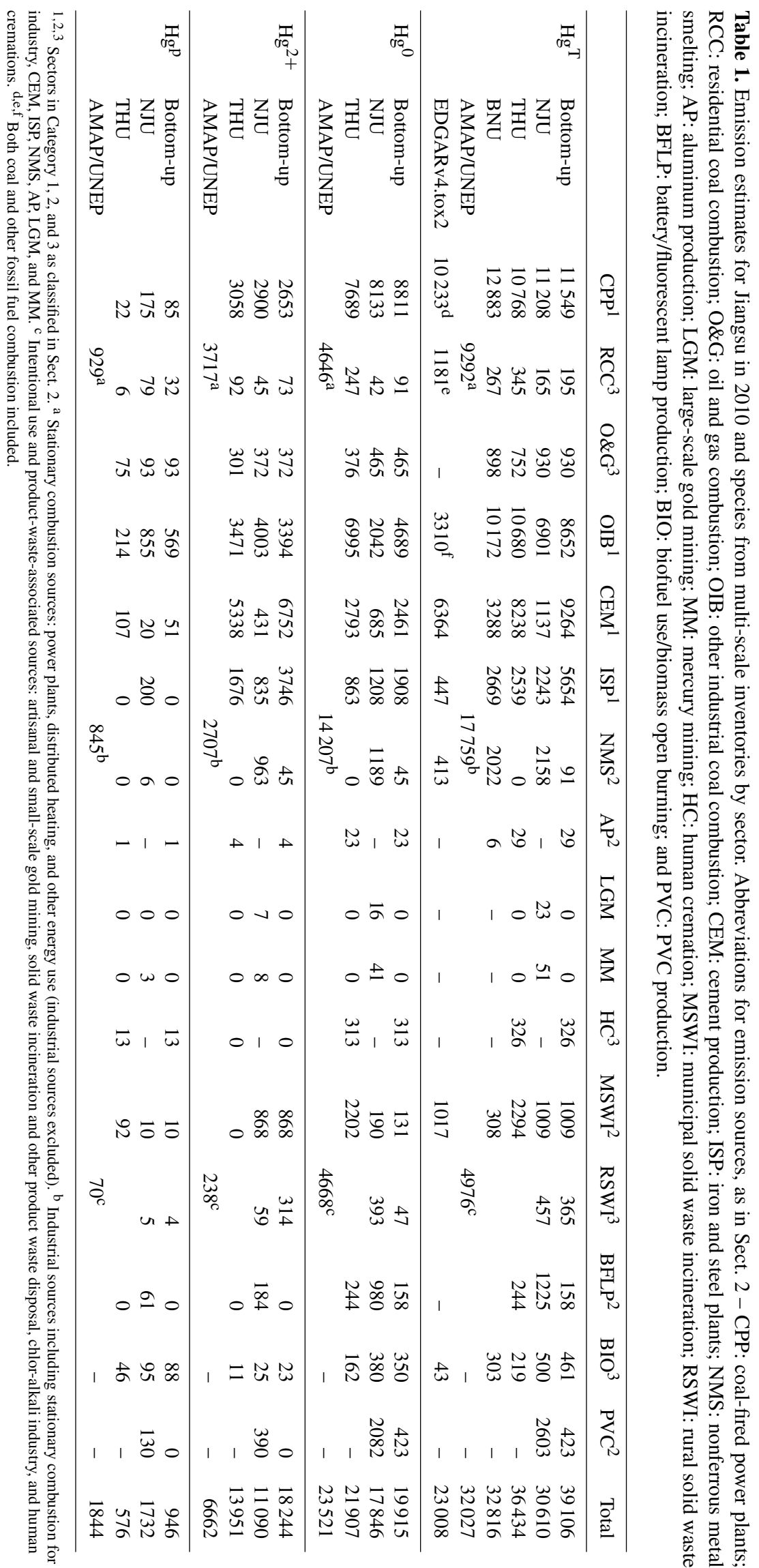


In national and provincial inventories, as mentioned in Sect. 2, the $\mathrm{Hg}$ contents in the raw coal $\left(\mathrm{HgC}_{\text {raw }}\right)$ consumed by province are estimated using an inter-provincial flow matrix for coal transport based on the results of field measurements on $\mathrm{Hg}$ contents for given coal mines (Tian et al., 2010, 2014; Zhang et al., 2012). The $\mathrm{HgC}_{\text {raw }}$ for Jiangsu in THU and our provincial inventory come from Zhang et al. (2012), who merged the results of two comprehensive measurement studies on $\mathrm{HgC}_{\text {raw }}$ (by themselves and USGS, 2004) for coal mines across China after 2000, and the average value is calculated at $0.2 \mathrm{~g} \mathrm{t}^{-1}$ coal. The NJU inventory adopted the $\mathrm{HgC}_{\text {raw }}$ of $0.169 \mathrm{~g} \mathrm{t}^{-1}$ coal from Tian et al. (2010), while the BNU inventory determined $\mathrm{HgC}_{\text {raw }}$ at $0.25 \mathrm{~g} \mathrm{t}^{-1}$ coal with a bootstrap simulation based on a thorough investigation of published data (Tian et al., 2014). $\mathrm{HgC}_{\text {raw }}$ in the $\mathrm{NJU}$ and $\mathrm{BNU}$ inventories are $15 \%$ smaller and $25 \%$ higher than that in the provincial inventory, leading to differences of 1746 and $2816 \mathrm{~kg}$ in $\mathrm{Hg}$ emissions, respectively. Given the large differences in $\mathrm{HgC}_{\text {raw }}$ between countries, global inventories applied national specific IEFs based on the domestic tests (UNEP, 2011b; Wang et al., 2010). The IEFs for China applied in AMAP/UNEP and EDGARv4.tox2, without considering the regional differences in $\mathrm{HgC}_{\text {raw }}$, are 26 and $28 \%$ lower than that in the provincial inventory (recalculated with $\mathrm{HgC}_{\text {raw }}$ and $\mathrm{RR}$ ). As regional $\mathrm{HgC}_{\text {raw }}$ differs a lot from the national average and could be largely influenced by the data selected, a large discrepancy might exist when the national value is applied in the regional inventory, and more regionalspecific measurements are suggested for reducing the uncertainty.

Total abatement rate (TA) of APCDs installed for CPP is calculated at $57 \%$ in the provincial inventory, 6.7 and $8.2 \%$ smaller than that in the THU and AMAP/UNEP inventories, respectively, and $12 \%$ larger than that in the NJU inventory. The differences result mainly from the varied removal efficiencies (RE) and application ratios (AR), as shown in Table S5. For RE, local tests on FF, ESP + FGD, and SCR + ESP + FGD were conducted by JSEMC (2013) and Xie and Yin (2014), and the results (provided in Table S2) are applied in the provincial inventory. From investigation of individual plants, the AR of FGD systems with relatively large benefits on $\mathrm{Hg}$ removal was underestimated in NJU and overestimated in the THU inventory. In the AMAP/UNEP inventory, relevant parameters were obtained from national comment, and elevated TA was estimated due to the larger AR of FF and FGD and the higher RE of FGD + ESP compared to that obtained from detailed source investigation in the provincial inventory.

For OIB, the comparison of $\mathrm{HgC}$ is similar to that for CPP. $\mathrm{AL}$ from the PSC in the provincial inventory is very close to that in the THU inventory obtained from NSB (2011b), while AL in the NJU inventory was much lower as the coal consumption of CEM and ISP was excluded. The RR from industrial boilers in this work is estimated at $82 \%$ based on domestic measurements (Wang et al., 2000; Tang et al.,
2004), much lower than the result in the THU inventory measured by Zhang et al. (2012), i.e., $95 \%$ for stoker-fired boilers. Given the limited samples in both inventories, large uncertainty exists in RR of industrial boilers. Compared to the provincial inventory, ARs of ESP and FGD were clearly underestimated in the NJU and THU inventories (Table S5); hence, the TA in NJU was calculated $23 \%$ smaller than that in the provincial inventory, leading to a $747 \mathrm{~kg}$ increase in the $\mathrm{Hg}$ emission estimate. In the THU inventory, however, the much higher RE of WET reduced the difference between national and provincial inventories, and TA in the THU inventory was only $2 \%$ smaller than the provincial one.

\subsubsection{Sensitivity analysis for cement and iron and steel industries}

For CEM, both the provincial and THU inventories adopted the data from Yang (2014), who measured provincial Hg contents in raw materials (limestone and other raw materials) and $\mathrm{Hg}$ removal efficiency of DPT + DR in China. For AL, the limestone consumption were calculated based on the clinker and cement production of individual plants in the provincial inventory, while THU relied on cement production at provincial level, leading to $13 \%$ smaller in AL and $1019 \mathrm{~kg}$ reduction in the $\mathrm{Hg}$ emission estimate. In addition, consumption of other raw materials for CEM was ignored in the THU inventory, leading to $1223 \mathrm{~kg}$ smaller in emission estimate compared to the provincial inventory. According to an on-site survey by Yang (2014), fly ash is $100 \%$ reused in DPT+DR, and thus the technology minimizes the $\mathrm{Hg}$ removal by dust collectors (ESP or FF). The AR of DPT + DR in THU was estimated at $82 \%$ at national average level, while it reaches $89 \%$ in Jiangsu based on detailed provincial statistics (CCA, 2011). Hence, the TA employed in THU is $25 \%$ larger than that in the provincial inventory, resulting in $259 \mathrm{~kg}$ underestimation in $\mathrm{Hg}$ emissions. The NJU and AMAP/UNEP inventories failed to characterize the poor control of $\mathrm{Hg}$ from DPT + DR. EFs applied in NJU came from early domestic measurements on rotary and shaft kiln (Li, 2011; Zhang, 2007), ignoring the recent penetration of DPT + DR. In the AMAP/UNEP inventory, an effective $\mathrm{Hg}$ capture of $40 \%$ was generally assumed for China's cement plants, taking only the use of ESP and FF into account. The TA was estimated $215 \%$ larger than that in the provincial inventory, resulting in a $2253 \mathrm{~kg}$ reduction in the $\mathrm{Hg}$ emission estimate. EDGAR applied uniform emission factor (UEF) of $0.065 \mathrm{~g} \mathrm{t}^{-1}$ clinker from EEA (2009), $32 \%$ lower than the average EF in the provincial inventory. BNU developed S-shaped curves to estimate the time-varying dynamic emission factors for noncoal combustion sector, based on the assumption of a gradually declining trend in EFs along with increased controls of APCDs. As mentioned above, however, the trend was not suitable for CEM due to the penetration of DPT + DR. Thus, $\mathrm{UEF}$ of $0.02 \mathrm{~g} \mathrm{t}^{-1}$ cement estimated in BNU might result in 
underestimation in $\mathrm{Hg}$ emissions, e.g., $7261 \mathrm{~kg}$ smaller than our provincial inventory.

For ISP, difficulty exists in emission estimation due to various $\mathrm{Hg}$ input sources and complex production processes, and there is no consistent method in multi-scale inventories so far. It was found that raw material production (limestone and dolomite), coking, sintering, and pig iron smelting with blast furnace account for most $\mathrm{Hg}$ emissions in typical ISPs in China (Wang et al., 2016). In our study, 11 factories containing those processes are collected in the PSC, and the emissions factors of 0.043 and $0.068 \mathrm{~g} \mathrm{t}^{-1}$ crude steel from Wang et al. (2016) are applied to plants with and without raw material production, respectively. In other inventories, very few results from domestic measurements were applied for $\mathrm{Hg}$ emission estimation for ISP in China. NJU took only coal combustion into account and thus underestimated the emissions for the sector by neglecting the $\mathrm{Hg}$ input along with iron ore, limestone and other raw materials. THU applied an emission factor of $0.04 \mathrm{~g} \mathrm{t}^{-1}$ from Pacyna et al. (2010) for crude steel production. Besides differences in emission factors, THU did not count the pig iron production in AL estimation, and thus AL in the THU inventory is $29 \%$ lower than that in the provincial inventory, resulting in $1615 \mathrm{~kg}$ reduction in the $\mathrm{Hg}$ emission estimate. Average $\mathrm{EF}$ in AMAP/UNEP was estimated at $0.039 \mathrm{~g} \mathrm{t}^{-1}$ pig iron by combining the input factor $\left(0.05 \mathrm{~g} \mathrm{t}^{-1}\right.$ pig iron) calculated with a mass-balance method (UNEP, 2011a; Remus et al., 2012), and the removal effects of APCDs. For comparison, $\mathrm{EF}$ used in our provincial inventory was recalculated at $0.064 \mathrm{~g} \mathrm{t}^{-1}$ pig iron based on the hot metal charging ratio $(R$ in Eq. 5; Remus et al., 2012). Lower EF in AMAP/UNEP can partly be attributed to the overestimated AR of APCDs in ISP without considering the gradual penetration of dust recycling as in CEM.

In general, the detailed activity and technology information including manufacturing procedures and APCDs was investigated for individual plants in our provincial inventory to improve the emission estimation, in contrast to previous inventories that applied simplified or regional-average data. However, some crucial parameters (e.g., $\mathrm{Hg}$ contents in coal and limestone, and Hg removal efficiencies of APCDs) are still unavailable at plant level due to a lack of measurements. Such a limitation indicates the necessity of more efforts on plant-specific emission factors and also motivates the uncertainty analysis for the provincial inventory, as presented in Sect. 3.4.

\subsubsection{Comparisons of emissions for categories 2 and 3}

For categories 2 and 3, differences also exist in EF and AL between inventories. For example, an emission factor of $0.22 \mathrm{~g} \mathrm{t}^{-1}$ waste combusted for MSWI based on domestic tests (L. Chen et al., 2013; Hu et al., 2012) is applied in the provincial inventory, while THU applied $0.5 \mathrm{~g} \mathrm{t}^{-1}$ from UNEP (2011a), resulting in a difference of $1024 \mathrm{~kg}$ in emis- sion estimate. For primary $\mathrm{Cu}$ production, the provincial inventory applied the emission factor of $0.4 \mathrm{~g} \mathrm{t}^{-1} \mathrm{Cu}$ from $\mathrm{Wu}$ et al. (2012), who incorporated the results of available field measurements and the penetrations of different smelting processes in China. BNU, however, applied a much higher emission factor at $8.9 \mathrm{~g} \mathrm{t}^{-1} \mathrm{Cu}$ estimated by using an $\mathrm{S}$-shaped curve based on international results (Habashi, 1978; Nriagu, 1979; Pacyna, 1984; Pacyna and Pacyna, 2001; Streets et al., 2011; EEA, 2013). In the NJU inventory, the emissions from NMS and IUS were estimated much higher than the provincial inventory, attributed largely to the different sources of activity data. For NMS, activity levels in the NJU and provincial inventories were obtained from NSB (2011c) and NMIA (2011), respectively. While NMIA (2011) provides the information on the production of primary nonferrous metal (the major source of $\mathrm{Hg}$ emissions for NMS), the secondary production was included in NSB (2011c), leading to a possible overestimate in $\mathrm{AL}$ and thus $\mathrm{Hg}$ emissions. For IUS, provincial $\mathrm{Hg}$ consumption was allocated from the national total use weighted by GDP in the NJU inventory, while the data are directly derived for Jiangsu from internal industrial report in the provincial inventory. In the global inventories, moreover, all the emissions for categories 2 and 3 in Jiangsu were downscaled from national estimations attributed to a lack of provincial information, and large bias could be expected. For example, the large discrepancy for intentional use and product-waste-associated sources between downscaled global and provincial inventories is likely attributed to the overestimation in emissions from artisanal and small-scale gold mining (ASGM) by global inventory (not included in Table 1 as no ASGM was found by local source investigation).

\subsection{Hg speciation analysis of multi-scale inventories}

Besides the total emissions, $\mathrm{Hg}$ speciation has a significant impact on the distance of $\mathrm{Hg}$ transport and chemical behaviors. Table 2 summarizes the mass fractions of $\mathrm{Hg}$ species in emissions by sector for multi-scale inventories.

In general, as shown in Table 2, reduced $\mathrm{Hg}^{0}$, but enhanced $\mathrm{Hg}^{2+}$, is estimated as the spatial scale gets smaller. This can be mainly explained by the use of domestic measurement results on $\mathrm{Hg}$ speciation for CEM, ISP, and MSWI in the provincial inventory. For CEM, the $\mathrm{Hg}^{2+}$ mass fraction for the dominant DPT + DR technology tends to reach $75 \%$ based on available measurements (Yang, 2014), leading to a much larger fraction of $\mathrm{Hg}^{2+}$ emissions in the provincial inventory. In contrast, speciated $\mathrm{Hg}$ emissions were calculated using the same speciation profiles as those for coal combustion in the NJU inventory or the uniform profile ignoring the effects of APCDs in the AMAP/UNEP inventory. For ISP, heterogeneous $\mathrm{Hg}$ oxidation can be enhanced by the high concentration of dust and existence of $\mathrm{Fe}_{2} \mathrm{O}_{3}$ in the flue gas during sintering process, leading to large $\mathrm{Hg}^{2+}$ fraction for the sector reaching $66 \%$ (Wang et al., 2016). For MSWI, 
Table 2. $\mathrm{Hg}$ speciation profiles by sector and the mass fractions to total emissions in multi-scale inventories (\%).

\begin{tabular}{|c|c|c|c|c|c|c|c|c|c|c|c|c|}
\hline \multirow[t]{2}{*}{ Sector } & \multicolumn{3}{|c|}{ Provincial inventory } & \multicolumn{3}{|c|}{ NJU } & \multicolumn{3}{|c|}{ THU } & \multicolumn{3}{|c|}{ AMAP/UNEP } \\
\hline & $\mathrm{Hg}^{0}$ & $\mathrm{Hg}^{2+}$ & $\mathrm{Hg}^{\mathrm{p}}$ & $\mathrm{Hg}^{0}$ & $\mathrm{Hg}^{2+}$ & $\mathrm{Hg}^{\mathrm{p}}$ & $\mathrm{Hg}^{0}$ & $\mathrm{Hg}^{2+}$ & $\mathrm{Hg}^{\mathrm{p}}$ & $\mathrm{Hg}^{0}$ & $\mathrm{Hg}^{2+}$ & $\mathrm{Hg}^{\mathrm{p}}$ \\
\hline СРP & 76 & 23 & 1 & 73 & 26 & 2 & 71 & 28 & 0 & 50 & 40 & 10 \\
\hline $\mathrm{RCC}$ & 46 & 37 & 16 & 25 & 27 & 48 & 71 & 27 & 2 & 50 & 40 & 10 \\
\hline $\mathrm{O} \& \mathrm{G}$ & 50 & 40 & 10 & 50 & 40 & 10 & 50 & 40 & 10 & 50 & 40 & 10 \\
\hline OIB & 54 & 39 & 7 & 30 & 57 & 13 & 66 & 33 & 2 & 50 & 40 & 10 \\
\hline CEM & 27 & 73 & 1 & 60 & 38 & 2 & 34 & 65 & 1 & 80 & 15 & 5 \\
\hline ISP & 34 & 66 & 0 & 54 & 37 & 9 & 34 & 66 & 0 & 80 & 15 & 5 \\
\hline NMS & 50 & 50 & 0 & 55 & 45 & 0 & - & - & - & 80 & 15 & 5 \\
\hline $\mathrm{AP}$ & 80 & 15 & 5 & - & - & - & 80 & 15 & 5 & 80 & 15 & 5 \\
\hline LGM & - & - & - & 70 & 30 & 0 & - & - & - & 80 & 15 & 5 \\
\hline MM & - & - & - & 80 & 15 & 5 & - & - & - & 80 & 20 & 0 \\
\hline ASGM & - & - & - & - & - & - & - & - & - & 100 & 0 & 0 \\
\hline $\mathrm{HC}$ & 96 & 0 & 4 & - & - & - & 96 & 0 & 4 & 80 & 15 & 5 \\
\hline MSWI & 13 & 86 & 1 & 13 & 86 & 1 & 96 & 0 & 4 & 20 & 60 & 20 \\
\hline BFLP & 100 & 0 & 0 & 80 & 15 & 5 & 100 & 0 & 0 & 80 & 15 & 5 \\
\hline $\mathrm{BIO}$ & 76 & 5 & 19 & 76 & 5 & 19 & 74 & 5 & 21 & - & - & - \\
\hline PVC & 100 & 0 & 0 & 80 & 15 & 5 & - & - & - & - & - & - \\
\hline Total & 51 & 47 & 2 & 57 & 37 & 6 & 60 & 38 & 2 & 73 & 21 & 6 \\
\hline
\end{tabular}

results of domestic measurements (L. Chen et al., 2013; Hu et al., 2012) were applied in the provincial and NJU inventories, elevating the $\mathrm{Hg}^{2+}$ fraction compared to THU and AMAP/UNEP inventories that applied a global uniform speciation profile without consideration of regional difference. It should be noted, however, that uncertainty exists in the estimation of speciated emissions at small spatial scale, attributed mainly to the limited samples in domestic measurements on CEM and ISP.

As mentioned above, the "universal" profiles were applied for many sectors in the AMAP/UNEP inventory, ignoring the effects of various types of APCDs on $\mathrm{Hg}$ speciation, particularly for coal combustion. However, the fate of $\mathrm{Hg}$ released to atmosphere can primarily be affected by the removal mechanisms of APCDs. As shown in Table 3, for example, $\mathrm{Hg}^{0}$ mass fractions for ESP + FGD and FF + FGD tend to be high, reaching 83 and $78 \%$, respectively, attributed to the relatively strong removal effects of APCDs on $\mathrm{Hg}^{2+}$ and $\mathrm{Hg}^{\mathrm{p}}$. Once SCR is applied, an increase in the $\mathrm{Hg}^{2+}$ fraction can be observed, as the catalyst in SCR system can accelerate the conversion of $\mathrm{Hg}^{0}$ to $\mathrm{Hg}^{2+}$ (Wang et al., 2010). In addition, $\mathrm{Hg}^{0}$ can also be oxidized to $\mathrm{Hg}^{2+}$ in $\mathrm{FF}$ attributed to specific chemical composition in flue gas (chlorine, for example) and to high temperature (Wang et al., 2008; He et al., 2012). Therefore, in contrast to global inventories, national and provincial inventories take the effects of different APCDs into account. Summarized in Table 3, considerable differences exist in the speciation profiles for typical APCDs between national and provincial inventories, attributed mainly to the various data used from domestic field measurements. Excluding the measurement results on
WET (Zhang et al., 2012), NJU assumed same species profile for WET and CYC, and thereby largely underestimated the mass fraction of $\mathrm{Hg}^{0}$ for OIB, where WET is widely applied. Furthermore, the penetrations of APCDs are also crucial in determination of speciated $\mathrm{Hg}$ emissions. As indicated in Table 3, with similar speciation profiles for FGD applied between multi-scale inventories, the difference in $\mathrm{Hg}$ speciation is relatively small for CPP between inventories, given the relatively accurate and transparent information on FGD penetration in CPP. For OIB, however, the difference in $\mathrm{Hg}$ speciation is significantly elevated, as large diversity in APCDs penetration is found between multi-scale inventories, as shown in Table S5. With the penetration of FF and ESP highly underestimated, for example, THU provided a lower estimation in $\mathrm{Hg}^{2+}$ fraction compared to other inventories.

\subsection{Comparisons of spatial patterns of emissions between multi-scale inventories}

Figure 3 presents the spatial distributions of total and speciated $\mathrm{Hg}$ emissions in Jiangsu province at $0.05^{\circ} \times 0.05^{\circ}$ (Zhong and Zhao, 2016). Similar patterns are found between species. Relatively high emissions are distributed over northwestern and southern Jiangsu, resulting from intensive coal combustion, as well as cement and iron and steel production, as indicated in Fig. S1 in the Supplement. As an important energy base, Xuzhou in northwestern Jiangsu contains a large number of coal combustion sources, while great energy demand exists in southern Jiangsu attributed to its developed economy and intensive industry. For cement production, as an example, the clinker manufacture plants that dom- 
Table 3. $\mathrm{Hg}$ speciation profiles used in provincial and national inventories for typical APCDs (\%).

\begin{tabular}{|c|c|c|c|c|c|c|c|c|c|c|}
\hline \multirow{3}{*}{\multicolumn{2}{|c|}{ Sources }} & \multicolumn{9}{|c|}{ Hg speciation } \\
\hline & & \multicolumn{3}{|c|}{ Provincial inventory } & \multicolumn{3}{|c|}{ NJU } & \multicolumn{3}{|c|}{ THU } \\
\hline & & $\mathrm{Hg}^{0}$ & $\mathrm{Hg}^{2+}$ & $\mathrm{Hg}^{\mathrm{p}}$ & $\mathrm{Hg}^{0}$ & $\mathrm{Hg}^{2+}$ & $\mathrm{Hg}^{\mathrm{p}}$ & $\mathrm{Hg}^{\mathrm{O}}$ & $\mathrm{Hg}^{2+}$ & $\mathrm{Hg}^{\mathrm{p}}$ \\
\hline \multirow[t]{8}{*}{ Coal combustion } & ESP & 57 & 41 & 1 & 65 & 35 & 0 & 58 & 41 & 1 \\
\hline & FF & 31 & 61 & 7 & 16 & 73 & 11 & 50 & 49 & 1 \\
\hline & WET & 65 & 33 & 2 & 30 & 57 & 13 & 65 & 33 & 2 \\
\hline & CYC & 30 & 57 & 14 & 30 & 57 & 13 & - & - & - \\
\hline & $\mathrm{ESP}+\mathrm{FGD}$ & 83 & 16 & 0 & 83 & 16 & 0 & 84 & 16 & 1 \\
\hline & $\mathrm{SCR}+\mathrm{ESP}+\mathrm{FGD}$ & 71 & 29 & 0 & 72 & 28 & 0 & 74 & 26 & 0 \\
\hline & $\mathrm{FF}+\mathrm{FGD}$ & 78 & 21 & 1 & - & - & - & 78 & 21 & 1 \\
\hline & No & 48 & 34 & 18 & 24 & 20 & 56 & 56 & 34 & 10 \\
\hline \multirow[t]{3}{*}{ CEM } & $\mathrm{DPT}+\mathrm{DR} / \mathrm{FF}^{*}$ & 24 & 75 & 1 & 16 & 73 & 11 & 24 & 76 & 1 \\
\hline & SKT/ESP* & 83 & 16 & 1 & 65 & 35 & 0 & 80 & 15 & 5 \\
\hline & RKT/WET* & 47 & 51 & 1 & 30 & 57 & 14 & 80 & 15 & 5 \\
\hline
\end{tabular}

* DPT + DR, SKT, and RKT are for the provincial and THU inventory (Zhang et al., 2015); FF, ESP, and WET are for the NJU inventory (Zhao et al., 2015a).

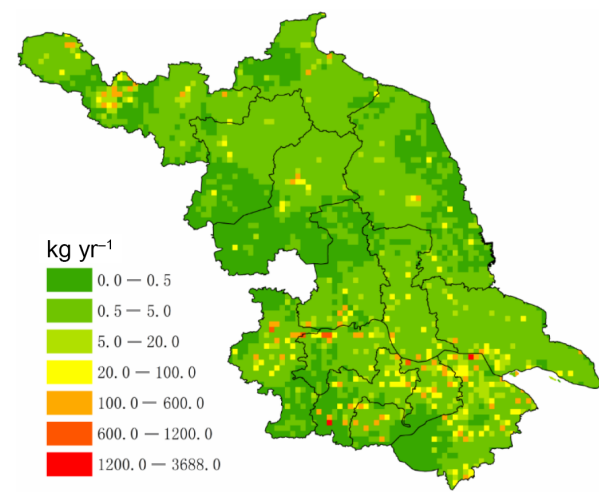

(a) $\mathrm{Hg}^{\mathrm{T}}$

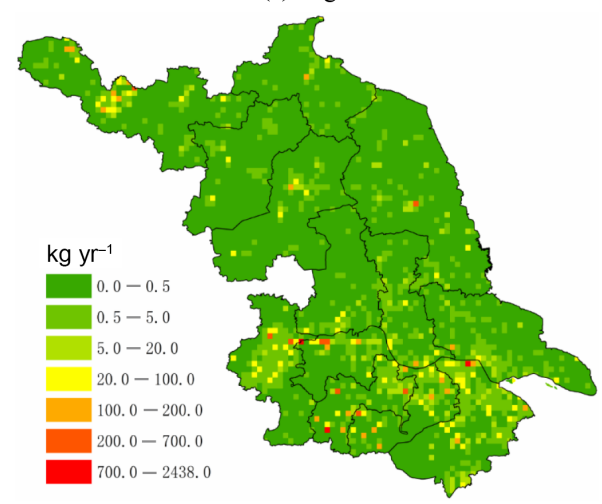

(c) $\mathrm{Hg}^{2+}$

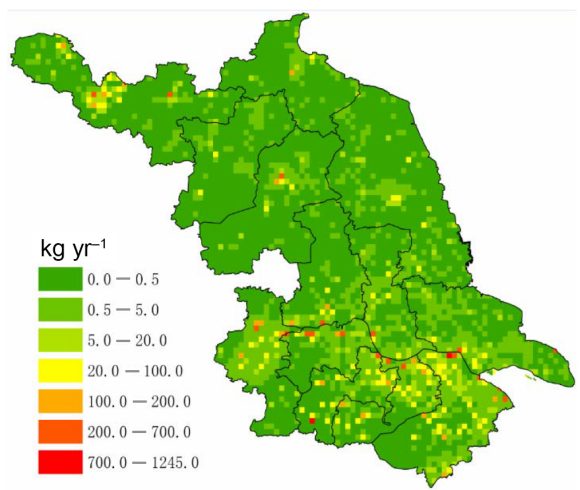

(b) $\mathrm{Hg}^{0}$

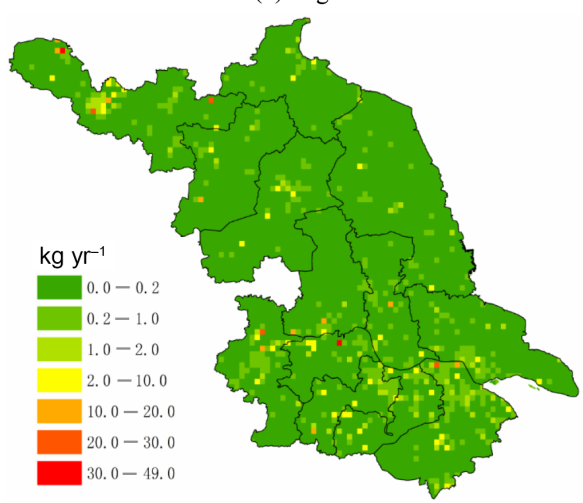

(d) $\mathrm{Hg}^{\mathrm{p}}$

Figure 3. Spatial distribution of $\mathrm{Hg}$ emissions for Jiangsu 2010 at a resolution of $0.05^{\circ} \times 0.05^{\circ}$ for $(\mathbf{a}) \mathrm{Hg}^{\mathrm{T}},(\mathbf{b}) \mathrm{Hg}^{0}$, (c) $\mathrm{Hg}^{2+}$, and (d) $\mathrm{Hg}^{\mathrm{p}}$.

inate the $\mathrm{Hg}$ emissions compared to the subsequent mixing stage (UNEP, 2011a) are mainly located in southern Jiangsu, depending on the distribution of limestone resources.

In order to compare the spatial distribution of the provincial inventory to that of the NJU, THU, AMAP/UNEP, and EDGARv4.tox2 inventories, we upscale the gridded provincial emissions from $0.05^{\circ} \times 0.05^{\circ}$ to the resolutions of $0.125^{\circ} \times 0.125^{\circ}, 36 \times 36 \mathrm{~km}, 0.5^{\circ} \times 0.5^{\circ}$, and $0.1^{\circ} \times 0.1^{\circ}$ respectively. Differences in gridded $\mathrm{Hg}^{\mathrm{T}}$ emissions for Jiangsu between the upscaled provincial inventory and 

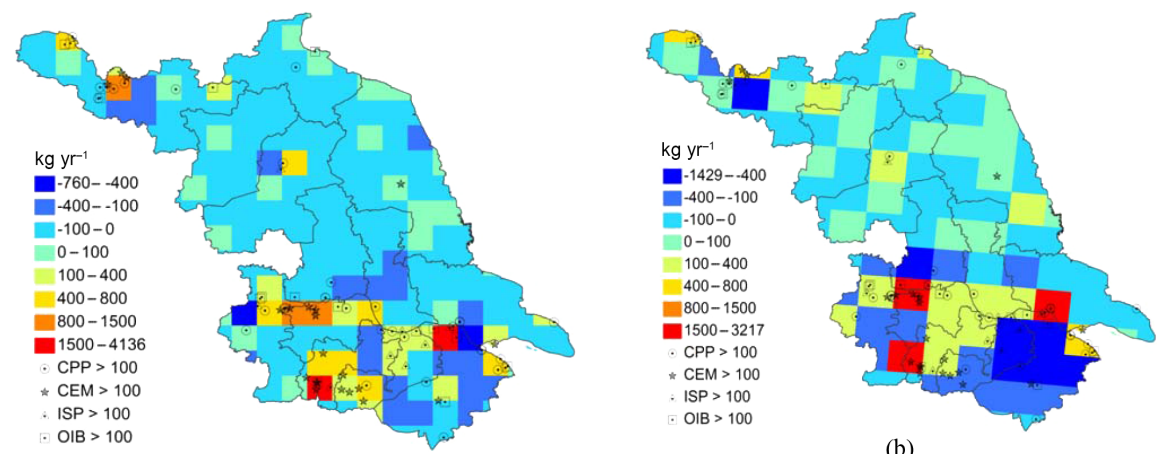

(b)

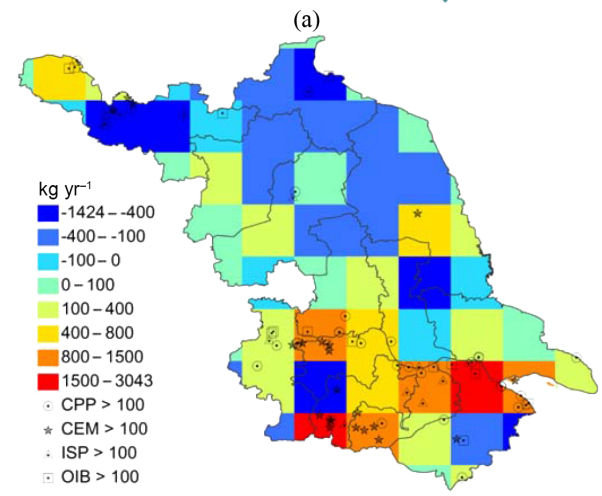

(c)

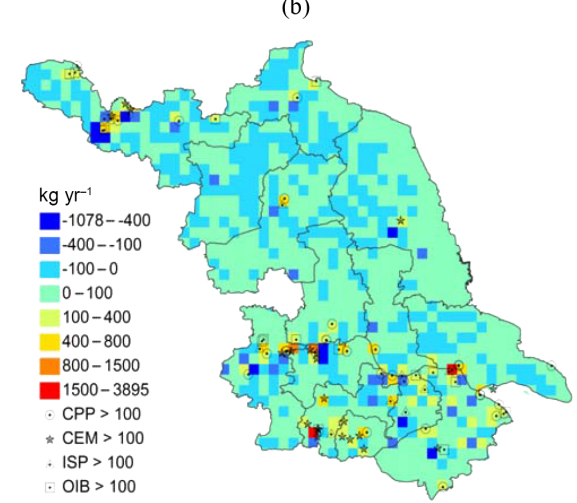

(d)

Figure 4. Differences in gridded $\mathrm{Hg}^{\mathrm{T}}$ emissions in Jiangsu 2010 between provincial and other inventories: emissions in the provincial inventory minus those in NJU (a), THU (b), AMAP/UNEP (c), and EDGARv4.tox2 (d). The locations of point sources with relatively large $\mathrm{Hg}$ emissions estimated in the provincial inventory are indicated in the panels as well.

other multi-scale inventories are presented in Fig. 4. Although selected sources were identified as point sources in global/national inventories, e.g., CEM in NJU and THU, ISP in EDGARv4.tox2, and CPP in all the inventories, the emission fraction of point sources (categories 1 and 2) is significantly elevated to $92 \%$ in the provincial inventory. In particular, the emissions from point sources of which the geographic information were corrected account for $78 \%$ of total emissions in the province.

As illustrated in Fig. 4, differences in gridded emissions between provincial and other inventories (NJU, THU, AMAP/UNEP, and EDGARv4.tox2) are respectively in the ranges of -760 to $+4135,-1429$ to $+3217,-1424$ to +3043 and -1078 to $+3895 \mathrm{~kg}$. Grids with differences more than $400 \mathrm{~kg} \mathrm{yr}^{-1}$ are commonly distributed in southern and northwestern Jiangsu, and coincide well with the locations of point sources with relatively large emissions in the provincial inventory. It can be indicated that differences in spatial patterns of $\mathrm{Hg}$ emissions come mainly from the inconsistent information on large point sources between the provincial inventory and national/global inventories. For CPP, AMAP/UNEP obtained information on identified facilities from Wikipedia (http://en.wikipedia.org/wiki/List_of_ power_stations_in_Asia) and failed to include a number of CPPs built in recent years (Steenhuisen and Wilson, 2015).
For EDGARv4.tox2, proxy data (e.g., electricity production) from Carbon Monitoring Action (CARMA, http://carma.org/ blog/carma-notes-future-data/) are used to allocate $\mathrm{Hg}$ emissions. Although CARMA incorporates all the major disclosure databases, uncertainties exist in certain individual plants attributed to a lack of information on geographical locations and control technologies. Moreover, as the most updated information in CARMA was collected in 2009, EDGAR had to predict the emissions of CPP for 2010 and could not fully track the actual changes in the sector, e.g., operation of newly built units or shutting down the small ones. Similarly, NJU and THU obtained information on power units from a relatively old database (Zhao et al., 2008) and made further assumptions on activities and penetrations of APCDs to update the emissions of individual plants. As a result, in general, larger emissions are found in the provincial inventory than other inventories in southern Jiangsu, where large power plants are located, particularly in Nanjing and northern Suzhou. As detailed information at plant level is unavailable for each inventory, we speculate that the discrepancy resulted mainly from the underestimation in (or missing) coal consumption in previous electric power generation databases that other inventories relied on, and from the use of regional/national-average information on APCD penetration by certain inventories (e.g., THU and AMAP/UNEP). 
The comparison in northwestern Jiangsu is less conclusive: the emissions in the areas with large power plants were estimated lower in the provincial inventory than AMAP/UNEP (Fig. 4c). Such a difference, however, results not only from the varied estimations in CPP emissions but also from discrepancy in other sources, e.g., intensive emissions from industrial sources in the area in AMAP/UNEP. For ISP and CEM, similarly, higher emissions were estimated by the provincial inventory for areas with large plants in Zhenjiang, Suzhou, and Changzhou in southern Jiangsu. In contrast to the provincial inventory that investigated the activities of each manufacturing processes for individual plants, the emissions in national inventories (THU and NJU) were allocated based only on the production of plants, ignoring the effects of manufacturing technologies on emissions. Moreover, some CEM and ISPs were missed in those national inventories, leading to underestimation in emissions for corresponding regions. When the national inventory was applied in CTM, the simulated concentrations of $\mathrm{Hg}^{\mathrm{T}}$ were usually lower than the observation at rural sites in eastern China (Wang et al., 2014). Since many large plants are being moved from urban to rural areas (Zhao et al., 2015b; Zhou et al., 2016), improvement in model performance could be expected when the elevated emissions in rural areas are estimated and used for CTM, incorporating the accurate information on individual large plants.

With much fewer large emitters, discrepancies in gridded emissions for another part of Jiangsu resulted largely from the allocation of emissions as area sources in national and global inventories. For example, in spite of an estimation of $8496 \mathrm{~kg}$ smaller than the provincial inventory in total emissions, the NJU inventory applied proxies (e.g., population and GDP) to allocate the emissions except those from CPP, resulting in higher emissions in central and most part of northern Jiangsu (Fig. 4). Similar patterns are also found for THU (Fig. 4b) and AMAP/UNEP (Fig. 4c) compared to the provincial inventory.

Besides the total emissions, differences in spatial distribution of speciated $\mathrm{Hg}$ emissions between multi-scale inventories are presented in Fig. S3 in the Supplement. The various patterns for species are largely influenced by the distribution of different types of large point sources, as the speciation profiles vary significantly between source types in the national and provincial inventories (Table 2). Compared to other inventories, larger $\mathrm{Hg}^{0}$ emissions were found in the provincial inventory in southern Jiangsu (particularly Zhenjiang and Taizhou), where CPPs with a large fraction of $\mathrm{Hg}^{0}$ are heavily concentrated. Elevated $\mathrm{Hg}^{2+}$ emissions were dominated by intensive CEM industry in Changzhou, Wuxi, and Zhenjiang in southern Jiangsu, as the $\mathrm{Hg}^{2+}$ fraction of CEM reaches $73 \%$ in the provincial inventory. Differences in $\mathrm{Hg}^{\mathrm{p}}$ emissions between inventories in central Jiangsu are closely related to the locations of OIB plants, attributed mainly to the relatively poor understanding of the particle control and thereby $\mathrm{Hg}^{\mathrm{p}}$ release of OIB. The emissions in the provincial inventory are larger than THU but smaller than AMAP/UNEP, as the $\mathrm{Hg}^{\mathrm{p}}$ mass fraction of OIB was assumed at $2 \%$ in THU, while it reached $10 \%$ in AMAP/UNEP (Table 2).

The vertical distribution of $\mathrm{Hg}$ releases, which is crucial for the transport range of atmospheric $\mathrm{Hg}$, is also analyzed. Four groups of release height are defined: 0-58, 58-141, 141-250, and $>250 \mathrm{~m}$. Based on the detailed information on emission sources, the fractions of $\mathrm{Hg}$ releases into the four groups for CPP are 2, 66, 31, and $1 \%$, respectively, and the analogue numbers for OIB, ISP, and CEM are $85,13,2$, and $0 ; 4,44,12$, and $4 \%$; and $6,94,0$, and $0 \%$, respectively. The release heights for rest sources are uniformly assumed to be in the range of $0-58 \mathrm{~m}$. As a result, the fractions of total $\mathrm{Hg}$ emissions in the four groups are estimated as 35, 53, 11 , and $1 \%$. In the AMAP/UNEP inventory, as a comparison, the fractions at the height of $0-50,50-150$, and $>150 \mathrm{~m}$ were estimated at 23,53 , and $24 \%$ respectively, with a larger share in $\mathrm{Hg}$ emitted over $150 \mathrm{~m}$ than that in our provincial inventory. The smaller fraction of $\mathrm{Hg}$ emissions under $150 \mathrm{~m}$ and larger fraction of $\mathrm{Hg}^{2+}$ as discussed in Sect. 3.2 in the provincial inventory are expected to result in more local deposition and less long-range transport compared to previous inventories when they are applied in the CTM. The reemissions of legacy $\mathrm{Hg}$ could then be enhanced and make a significant contribution to atmospheric $\mathrm{Hg}$ concentrations, as indicated by Zhu et al. (2012).

\subsection{Uncertainty in the provincial inventory}

As summarized in Table 4, the uncertainties in speciated $\mathrm{Hg}$ emissions in the provincial inventory are estimated at -24 to $+82 \%$ (95\% confidence intervals around central estimates), -34 to $+99,-23$ to 68 , and -34 to $+270 \%$ for $\mathrm{Hg}^{\mathrm{T}}, \mathrm{Hg}^{0}$, $\mathrm{Hg}^{2+}$, and $\mathrm{Hg}^{\mathrm{p}}$, respectively. For comparison, the uncertainties in Jiangsu emissions from major sectors including CPP, CEM, ISP, and OIB in NJU inventory are recalculated following Zhao et al. (2015a) and provided in Table 4 as well. The uncertainties for major sources in the provincial inventory were smaller than those in the NJU inventory, attributed largely to the bottom-up approach used in the provincial inventory with more accurate information on activity levels and APCDs applications for individual plants of Category 1. In addition, with more field measurements of $\mathrm{Hg}$ contents in coal and limestone incorporated, the uncertainties in $\mathrm{HgC}_{\text {raw }}$ and $\mathrm{HgC}_{\text {Limestone }}$ are significantly reduced, resulting from the mechanism of error compensation when $\mathrm{HgC}_{\text {raw }}$ of coals produced in different provinces is taken into account in the inter-provincial flow model for coal transport and from the success in bootstrap simulation, respectively. As a result, the uncertainties in emissions from CPP, OIB, and CEM are effectively reduced in the provincial inventory.

The parameters contributing most to uncertainties and their contributions to the variance of corresponding emission estimates are summarized by sector in Table S8 in the Sup- 
Table 4. Uncertainties in $\mathrm{Hg}$ emissions in Jiangsu in provincial and national (NJU) inventories by source, expressed as the $95 \%$ confidence intervals of central estimates.

\begin{tabular}{llrrrr}
\hline & Sources & $\mathrm{Hg}^{\mathrm{T}}$ & $\mathrm{Hg}^{0}$ & $\mathrm{Hg}^{2+}$ & $\mathrm{Hg}^{\mathrm{p}}$ \\
\hline Provincial & CPP & $(-59,+147 \%)$ & $(-64,+131 \%)$ & $(-56,+244 \%)$ & $(-43,+418 \%)$ \\
& CEM & $(-15,+58 \%)$ & $(-36,+87 \%)$ & $(-18,+63 \%)$ & $(-57,+218 \%)$ \\
& ISP & $(-38,+53 \%)$ & $(-33,+156 \%)$ & $(-62,+44 \%)$ & - \\
& OIB & $(-52,+138 \%)$ & $(-55,+133 \%)$ & $(-55,+146 \%)$ & $(-67,+329 \%)$ \\
& Rest sources & $(-25,+133 \%)$ & $(-20,+151 \%)$ & $(-67,+168 \%)$ & $(-43,+367 \%)$ \\
& Total & $(-26,+81 \%)$ & $(-34,+99 \%)$ & $(-23,+68 \%)$ & $(-34,+270 \%)$ \\
\hline \multirow{2}{*}{ NJU } & CPP & $(-80,+198 \%)$ & $(-80,+198 \%)$ & $(-80,+201 \%)$ & $(-75,+477 \%)$ \\
& CEM & $(-62,+97 \%)$ & $(-75,+140 \%)$ & $(-63,+82 \%)$ & $(-73,+266 \%)$ \\
& ISP & $(-81,+167 \%)$ & $(-82,+157 \%)$ & $(-82,+170 \%)$ & $(-81,+250 \%)$ \\
& OIB & $(-83,+153 \%)$ & $(-97,+218 \%)$ & $(-97,+228 \%)$ & $(-87,+170 \%)$ \\
\hline
\end{tabular}

plement. For CPP and OIB, parameters related to emission factors contribute most to the uncertainties in $\mathrm{Hg}^{\mathrm{T}}$ emissions, including the $\mathrm{HgC}_{\mathrm{raw}}$ in provinces with largest contribution to the input of coal consumed in Jiangsu (i.e., Shaanxi and Inner Mongolia), and the removal efficiencies (RE) or release ratios (RR) of $\mathrm{Hg}$ for typical APCD (ESP+FGD) and combustor type (grate boiler). $\mathrm{HgC}_{\text {raw }}$ of coals produced in Shaanxi and Inner Mongolia, which collectively accounted for $34 \%$ of coal consumption in Jiangsu, contributed respectively 26 and $18 \%$ to the uncertainties in $\mathrm{Hg}$ emissions for CPP and 15 and $11 \%$ to those for OIB. It is thus essential to conduct systematic and synergetic measurements on $\mathrm{HgC}_{\text {raw }}$ in different regions (particularly those with large coal production) to constrain the uncertainties in $\mathrm{Hg}$ emission estimation for coal combustion sources, at both regional and national scales. Given the wide application of ESP + FGD in CPP (70\% in coal consumption), $\mathrm{RE}_{\mathrm{ESP}}+\mathrm{FGD}$ is estimated to contribute $20 \%$ to $\mathrm{Hg}$ emissions from CPP. Local measurements on RE of typical APCDs, which have started in Jiangsu (JSEMC, 2013; Xie and Yin, 2014), are expected to potentially improve the $\mathrm{Hg}$ emission estimation at the regional level. Although grate boilers were applied in $92 \%$ of OIB plants in Jiangsu, there are very few studies on their $\mathrm{Hg}$ release rate, resulting in a contribution of $5 \%$ to the emission uncertainty. For CEM, $\mathrm{HgC}_{\text {Limestone }}$ dominates the uncertainties in $\mathrm{Hg}$ emissions, with the contribution estimated at $84 \%$. Attributed to a lack of detailed information, provincial average of $\mathrm{HgC}_{\text {Limestone }}$ with the lognormal distribution fitted through bootstrap simulation based on available measurements (Fig. S2 and Table S6) was uniformly applied for all the individual plants, leading to the enhanced contribution to the uncertainty. For ISP, EF of limestone and dolomite production contributes $60 \%$ to $\mathrm{Hg}$ emissions, as the process is estimated to account for $88 \%$ of emissions from the entire sector. In addition, AL from the largest ISP factory, which accounted for 40 and $75 \%$ of pig iron and crude steel production for the whole province, respectively, contributes $24 \%$ to the total uncertainty in the ISP sector. The result indicates a necessity of specific investigation of super emitters. For rest sources, MSWI, BIO, and O\&G are the largest sources for $\mathrm{Hg}^{\mathrm{T}}$ emissions, and EFs of those types of sources thus contribute most to the emission uncertainty.

In most cases, parameters with largest contribution to uncertainty in $\mathrm{Hg}^{\mathrm{T}}$ also play crucial roles in the uncertainty in speciated emissions. Moreover, the speciation profiles for typical source types and APCDs are identified as key parameters to the uncertainties in speciated emissions as well. For example, the mass fractions of $\mathrm{Hg}^{2+}$ from ESP+FGD and that of $\mathrm{Hg}^{\mathrm{p}}$ from ESP are the largest contributors to uncertainties in $\mathrm{Hg}^{2+}$ and $\mathrm{Hg}^{\mathrm{p}}$ emissions from CPP, respectively. For OIB, the mass fraction of $\mathrm{Hg}^{\mathrm{p}}$ from sources without any control is much higher than that with APCDs (Table 3); thus, it plays an important role in the emission uncertainty, with the contribution estimated at $35 \%$. For CEM and ISP, studies on speciation profiles are limited so far, and the speciation profiles for DPT + DR and ISP plants contribute largely to uncertainties in speciated emissions.

\section{Conclusions}

Taking Jiangsu province in China as an example, we have thoroughly analyzed the discrepancies and their sources of atmospheric $\mathrm{Hg}$ emission estimations in multi-scale inventories, applying various methods and data. Using a bottomup approach that integrates the best available information on individual plants and most recent field measurements, we find that the total $\mathrm{Hg}$ emissions in Jiangsu in 2010 are estimated larger than any other national/global inventories. CPP, ISP, CEM, and OIB collectively accounted for $90 \%$ of the total emissions. Comparisons between available studies demonstrate that the information gaps of multi-scale inventories lead to large differences in $\mathrm{Hg}$ emission estimation. Discrepancies in emissions between inventories for the above-mentioned major sources come primarily from various data sources for activity levels, $\mathrm{Hg}$ contents in coals, and total abatement effects of APCDs. A notable increase 
in $\mathrm{Hg}^{2+}$ emissions is estimated with the bottom-up approach compared to other global/national inventories, attributed mainly to the adoption of domestic measurement results with elevated mass fraction of $\mathrm{Hg}^{2+}$ for CEM, ISP, and MSWI. Inconsistent information on large point sources lead to large differences in spatial distribution of emissions between provincial and other inventories, particularly in the south and northwest of the province, where intensive coal combustion and industry are located. Improved estimates in emission level, speciation, and spatial distribution are expected to better support the regional chemistry transport modeling of atmospheric $\mathrm{Hg}$. Compared to the national inventory, uncertainties in $\mathrm{Hg}$ emissions are reduced in the provincial inventory using the bottom-up approach.

The method developed and demonstrated for Jiangsu could potentially be applied to other provinces, particularly for those with intensive industrial plants. As estimated in this work, for example, cement and iron and steel industries were the two most important sectors in which the $\mathrm{Hg}$ emissions were significantly underestimated by previous inventories for Jiangsu. The underestimations came mainly from ignoring the high $\mathrm{Hg}$ release ratio of precalciner technology with dust recycling, as well as from the application of relatively low emission factors for steel production. We could thus cautiously infer that $\mathrm{Hg}$ emissions might be underestimated for China's other regions with intensive cement and steel industries in previous inventories. For power plants and industrial boilers, however, the $\mathrm{Hg}$ emissions were influenced largely by $\mathrm{Hg}$ contents in coal and APCD application. Whether the emissions of those sources were underestimated or not for other parts of the country could hardly be judged unless detailed information becomes available for the regions. Extensive and dedicated measurements are urgently required for $\mathrm{Hg}$ contents in coal/limestone and removal efficiency of dominant APCDs to further improve the emission estimation at regional/local scales and, eventually, for the whole country.

\section{Data availability}

The gridded Hg emissions for Jiangsu province 2010 at a horizontal resolution of $0.05^{\circ} \times 0.05^{\circ}$ can be downloaded at http://www.airqualitynju.com/En/Data/List/Datadownload (Zhong and Zhao, 2016).

\section{The Supplement related to this article is available online at doi:10.5194/acp-16-15119-2016-supplement.}

Acknowledgements. This work was sponsored by the Natural Science Foundation of China (91644220 and 41575142), the Natural Science Foundation of Jiangsu (BK20140020), the Ministry of
Science and Technology of China (2016YFC0201507), the Jiangsu Science and Technology Support Program (SBE2014070918), and the Special Research Program of Environmental Protection for Commonweal (201509004). We would like to acknowledge Hezhong Tian from Beijing Normal University and Simon Wilson from the UNEP/AMAP Expert Group for the detailed information on national/global $\mathrm{Hg}$ emission inventories. Thanks also go to the two anonymous reviewers for their very valuable comments to improve this work.

Edited by: L. Zhang

Reviewed by: two anonymous referees

\section{References}

AMAP/UNEP: Technical Background Report for the Global Mercury Assessment, Arctic Monitoring and Assessment Programme, Oslo, Norway/UNEP Chemicals Branch, Geneva, Switzerland, 263 pp., 2013.

Chen, L., Liu, M., Fan, R., Ma, S., Xu, Z., Ren, M., and He, Q.: Mercury speciation and emission from municipal solid waste incinerators in the Pearl River Delta, South China, Sci. Total Environ., 447, 396-402, 2013.

China Cement Association (CCA): China cement almanac, China Building Industry Press, Beijing, China, 2011.

European Environment Agency (EEA): EMEP/EEA air pollutant emission inventory guidebook 2009, Technical report No 9/2009, available at: http://www.eea.europa.eu/publications/ emep-eea-emission-inventory-guidebook-2009 (last access: 3 December 2016), 2009.

European Environment Agency (EEA): EMEP/EEA air pollutant emission inventory guidebook 2013, available at: http://www. eea.europa.eu/publications/emep-eea-guidebook-2013 (last access: 3 December 2016), 2013.

Fu, X. W., Feng, X. B., Sommar, J., and Wang, S. F.: A review of studies on atmospheric mercury in China, Sci. Total Environ, 421-422, 73-81, 2012.

Fu, X. W., Zhang, H., Lin, C.-J., Feng, X. B., Zhou, L. X., and Fang, S. X.: Correlation slopes of GEM / CO, GEM / $\mathrm{CO}_{2}$, and $\mathrm{GEM} / \mathrm{CH}_{4}$ and estimated mercury emissions in China, South Asia, the Indochinese Peninsula, and Central Asia derived from observations in northwestern and southwestern China, Atmos. Chem. Phys., 15, 1013-1028, doi:10.5194/acp-15-1013-2015, 2015.

Habashi, F.: Metallurgical plants: how mercury pollution is abated, Environ. Sci. Technol., 12, 1372-1376, 1978.

He, Z. Q., Kan, Z. N., Qi, L. M., and Han, X. F.: Analysis to mercury removal performance test of bag-type dust collector, Inner Mongolia Electric Power, 30, 40-42, 2012 (in Chinese).

Hu, D., Zhang, W., Chen, L., Ou, L. B., Tong, Y. D., Wei, W., Long, W. J., and Wang, X. J.: Mercury emissions from waste combustion in China from 2004 to 2010, Atmos. Environ., 62, 359-366, 2012.

Jiangsu Environment Monitoring Center (JSEMC): Research on mercury emissions in flue gas of coal-fired power plants in Jiangsu Province, Interim report, Nanjing, China, 2013 (in Chinese). 
Li, W.: Characterization of Atmospheric Mercury Emissions from Coal-fired Power Plant and Cement Plant, Master thesis, Xi'nan University, Chongqing, China, 2011 (in Chinese).

Lin, C.-J., Pan, L., Streets, D. G., Shetty, S. K., Jang, C., Feng, X., Chu, H.-W., and Ho, T. C.: Estimating mercury emission outflow from East Asia using CMAQ-Hg, Atmos. Chem. Phys., 10, 1853-1864, doi:10.5194/acp-10-1853-2010, 2010.

Muntean, M., Janssens-Maenhout, G., Song, S., Selin, N. E., Olivier, J. G. J., Guizzardi, D., Maas, R., and Dentener, F.: Trend analysis from 1970 to 2008 and model evaluation of EDGARv4 global gridded anthropogenic mercury emissions, Sci. Total Environ., 494-495, 337-350, 2014.

National Statistical Bureau of China (NSB): China Statistical Yearbook, China Statistics Press, Beijing, China, 2011a.

National Statistical Bureau of China (NSB): China Energy Statistical Yearbook, China Statistics Press, Beijing, China, 2011b.

National Statistical Bureau of China (NSB): China Industry Economy Statistical Yearbook, China Statistics Press, Beijing, China, 2011c.

Nonferrous Metal Industry Association of China (NMIA): Yearbook of Nonferrous Metals Industry of China, China Statistics Press, Beijing, China, 2011.

Nriagu, J. O.: Global inventory of natural and anthropogenic emissions of trace metals to the atmosphere, Nature, 279, 409-411, 1979.

Pacyna, E. G., Pacyna, J. M., Sundseth, K., Munthe, J., Kindbom, K., Wilson, S., Steenhuisen, F., and Maxson, P.: Global emission of mercury to the atmosphere from anthropogenic sources in 2005 and projections to 2020, Atmos. Environ., 44, 2487-2499, 2010.

Pacyna, J. M.: Estimation of the atmospheric emissions of trace elements from anthropogenic sources in Europe, Atmos. Environ., 18, 41-50, 1984.

Pacyna, J. M. and Pacyna, E. G.: An assessment of global and regional emissions of trace metals to the atmosphere from anthropogenic sources worldwide, Environ. Rev., 9, 269-298, 2001.

Pirrone, N. and Mason, R. P. (Eds.): Mercury fate and transport in the global atmosphere, Springer Science + Business Media, LLC, New York, USA, doi:10.1007/978-0-387-93958-2, 2009.

Pirrone, N., Cinnirella, S., Feng, X., Finkelman, R. B., Friedli, H. R., Leaner, J., Mason, R., Mukherjee, A. B., Stracher, G. B., Streets, D. G., and Telmer, K.: Global mercury emissions to the atmosphere from anthropogenic and natural sources, Atmos. Chem. Phys., 10, 5951-5964, doi:10.5194/acp-10-59512010, 2010.

Remus, R., Aguado-Monsonet, M. A., Roudier, S., and Delgado Sancho, L.: Best Available Techniques Reference Document (BREF) for Iron and Steel Production, Industrial Emissions Directive 2010/75/EU (Integrated Pollution Prevention and Control), European Commission, March, 2012, available at: http://eippcb.jrc.ec.europa.eu/reference/BREF/IS_Adopted_ 03_2012.pdf (last access: 3 December 2016), 2012.

Steenhuisen, F. and Wilson, S. J.: Identifying and characterizing major emission point sources as a basis for geospatial distribution of mercury emissions inventories, Atmos. Environ., 112, 167$177,2015$.

Streets, D. G., Devane, M. K., Lu, Z., Bond, T. C., Sunderland, E. M., and Jacob, D. J.: All-time releases of mercury to the atmo- sphere from human activities, Environ. Sci. Technol., 45, 1048510491, 2011.

Tang, S. L., Feng, X. B., Shang, L. H., Yan, H. Y., and Hou, Y. M.: Mercury speciation and emissions in the flue gas of a small-scale coal-fired boiler in Guiyang, Res. Environ. Sci., 17, 74-76, 2004 (in Chinese).

Tian, H. Z., Wang, Y., Xue, Z. G., Cheng, K., Qu, Y. P., Chai, F. H., and Hao, J. M.: Trend and characteristics of atmospheric emissions of $\mathrm{Hg}$, As, and Se from coal combustion in China, 1980 2007, Atmos. Chem. Phys., 10, 11905-11919, doi:10.5194/acp10-11905-2010, 2010.

Tian, H. Z., Liu, K. Y., Zhou, J. R., Lu, L., Hao, J. M., Qiu, P. P., Gao, J. J., Zhu, C. Y., Wang, K., and Hua, S. B.: Atmospheric Emission Inventory of Hazardous Trace Elements from Chinas Coal-Fired Power Plants Temporal Trends and Spatial Variation Characteristics, Environ. Sci. Technol., 48, 3575-3582, 2014.

Tian, H. Z., Zhu, C. Y., Gao, J. J., Cheng, K., Hao, J. M., Wang, K., Hua, S. B., Wang, Y., and Zhou, J. R.: Quantitative assessment of atmospheric emissions of toxic heavy metals from anthropogenic sources in China: historical trend, spatial distribution, uncertainties, and control policies, Atmos. Chem. Phys., 15, 10127-10147, doi:10.5194/acp-15-10127-2015, 2015.

Timmermans, R. M. A., Denier van der Gon, H. A. C., Kuenen, J. J. P., Segers, A. J., Honoré, C., Perrussel, O., Builtjes, P. J. H., and Schaap, M.: Quantification of the urban air pollution increment and its dependency on the use of down-scaled and bottom-up city emission inventories, Urban Climate, 6, 44-62, 2013.

United Nations Environment Programme (UNEP): Toolkit for Identification and Quantification of Mercury Releases, Revised Inventory Level 2 Report including Description of Mercury Source Characteristics, Version 1.1., January 2011, available at: www.unep.org/hazardoussubstances/ Portals/9/Mercury/Documents/Publications/Toolkit/

HgToolkit-Reference-Report-rev-Jan11.pdf (last access: 3 December 2016), 2011a.

United Nations Environment Programme (UNEP): Reducing Mercury Emissions from Coal Combustion in the Energy Sector of China, Prepared for the Ministry of Environment Protection of China and UNEP Chemicals, Tsinghua University, Beijing, China, February 2011, available at: www.unep.org/hazardoussubstances/Portals/9/Mercury/ Documents/coal/FINALChinese_CoalReport-11March2011.pdf (last access: 3 December 2016), 2011 b.

United States Geological Survey (USGS): Mercury content in coal mines in China, Reston, Virginia, USA, 2004.

US Environmental Protection Agency (USEPA): US National Emission Inventory 2008 version 2 (April 2012), available at: https://www.epa.gov/air-emissions-inventories/ 2008-national-emissions-inventory-nei-data (last access: 3 December 2016), 2012.

Wang, F. Y., Wang S. X., Zhang, L., Yang, H., Gao, W., Wu, Q. R., and Hao, J. M.: Mercury mass flow in iron and steel production process and its implications for mercury emission control, J. Environ. Sci., 43, 293-301, doi:10.1016/j.jes.2015.07.019, 2016.

Wang, L., Wang, S. X., Zhang, L., Wang, Y. X., Zhang, Y. X., Nielsen, C., McElroy, M. B., and Hao, J. M.: Source apportionment of atmospheric mercury pollution in China using the GEOS-Chem model, Environ. Pollut., 190, 166-175, 2014. 
Wang, Q. C., Shen, W. G., and Ma, Z. W.: Estimation of Mercury Emission from Coal Combustion in China, Environ. Sci. Technol., 34, 2711-2713, 2000.

Wang, S. X., Zhang, L., Li, G. H., Wu, Y., Hao, J. M., Pirrone, N., Sprovieri, F., and Ancora, M. P.: Mercury emission and speciation of coal-fired power plants in China, Atmos. Chem. Phys., 10, 1183-1192, doi:10.5194/acp-10-1183-2010, 2010.

Wang, Y. J., Duan, Y. F., Yang, L. G., Jiang, Y. M., Wu, C. J., Wang, Q., and Yang, X. H.: Analysis of the factors exercising an influence on the morphological transformation of mercury in the flue gas of a $600 \mathrm{MW}$ coal-fired power plant, Journal of Engineering for Thermal Energy and Power, 4, 399-403, 2008 (in Chinese).

Wu, Q. R., Wang, S. X., Zhang, L., Song, J. X., Yang, H., and Meng, Y.: Update of mercury emissions from China's primary zinc, lead and copper smelters, 2000-2010, Atmos. Chem. Phys., 12, 11153-11163, doi:10.5194/acp-12-11153-2012, 2012.

Xie, X. and Yin, W.: Nanjing Thermal Power Plant Boiler Flue Gas Mercury Emissions in the Survey, Environmental Monitoring and Forewarning, 6, 47-49, 2014.

Yang, H.: Study on atmospheric mercury emission and control strategies from cement production in China, Master thesis, Tsinghua University, Beijing, China, 2014 (in Chinese).

Zhang, L.: Research on mercury emission measurement and estimate from combustion resources, Master thesis, Zhejiang University, Hangzhou, China, 2007 (in Chinese).

Zhang, L., Wang, S. X., Meng, Y., and Hao, J. M.: Influence of mercury and chlorine content of coal on mercury emissions from coal-fired power plants in China, Environ. Sci. Technol., 46, 6385-6392, 2012.

Zhang, L., Wang, S. X., Wang, L., Wu, Y., Duan, L., Wu, Q. R., Wang, F. Y., Yang, M., Yang, H., Hao, J. M., and Liu, X.: Updated Emission Inventories for Speciated Atmospheric Mercury from Anthropogenic Sources in China, Environ. Sci. Technol, 49, 3185-3194, 2015.

Zhao, Y., Wang, S. X., Duan, L., Lei, Y., Cao, P. F., and Hao, J. M.: Primary air pollutant emissions of coal-fired power plants in China: current status and future prediction, Atmos. Environ., 42, 8442-8452, 2008.
Zhao, Y., Nielsen, C. P., Lei, Y., McElroy, M. B., and Hao, J.: Quantifying the uncertainties of a bottom-up emission inventory of anthropogenic atmospheric pollutants in China, Atmos. Chem. Phys., 11, 2295-2308, doi:10.5194/acp-11-2295-2011, 2011.

Zhao, Y., Zhong, H., Zhang, J., and Nielsen, C. P.: Evaluating the effects of China's pollution controls on inter-annual trends and uncertainties of atmospheric mercury emissions, Atmos. Chem. Phys., 15, 4317-4337, doi:10.5194/acp-15-4317-2015, $2015 \mathrm{a}$.

Zhao, Y., Qiu, L. P., Xu, R. Y., Xie, F. J., Zhang, Q., Yu, Y. Y., Nielsen, C. P., Qin, H. X., Wang, H. K., Wu, X. C., Li, W. Q., and Zhang, J.: Advantages of a city-scale emission inventory for urban air quality research and policy: the case of Nanjing, a typical industrial city in the Yangtze River Delta, China, Atmos. Chem. Phys., 15, 12623-12644, doi:10.5194/acp15-12623-2015, 2015b.

Zhong, H. and Zhao, Y.: Total and speciated $\mathrm{Hg}$ emissions of anthropogenic origin for Jiangsu China 2010 with a horizontal spatial resolution at $0.05^{\circ} \times 0.05^{\circ}$, available at: http:// www.airqualitynju.com/En/Data/List/Datadownload, last access: 3 December 2016.

Zhou, Y., Zhao, Y., Mao, P., Zhang, Q., Zhang, J., Qiu, L., and Yang, Y.: Development of a high-resolution emission inventory and its evaluation through air quality modeling for Jiangsu Province, China, Atmos. Chem. Phys. Discuss., doi:10.5194/acp2016-567, in review, 2016.

Zhu, J., Wang, T., Talbot, R., Mao, H., Hall, C. B., Yang, X., Fu, C., Zhuang, B., Li, S., Han, Y., and Huang, X.: Characteristics of atmospheric Total Gaseous Mercury (TGM) observed in urban Nanjing, China, Atmos. Chem. Phys., 12, 12103-12118, doi:10.5194/acp-12-12103-2012, 2012.

Zhu, J., Wang, T., Bieser, J., and Matthias, V.: Source attribution and process analysis for atmospheric mercury in eastern China simulated by CMAQ-Hg, Atmos. Chem. Phys., 15, 8767-8779, doi:10.5194/acp-15-8767-2015, 2015. 